\title{
Playing styles based on experiential learning theory
}

\author{
Citation for published version (APA):
}

Bontchev, B., Vassileva, D., Aleksieva-Petrova, A., \& Petrov, M. (2018). Playing styles based on experiential learning theory. Computers in Human Behavior, 85, 319-328. https://doi.org/10.1016/j.chb.2018.04.009

DOI:

10.1016/j.chb.2018.04.009

Document status and date:

Published: 01/08/2018

Document Version:

Version created as part of publication process; publisher's layout; not normally made publicly available

\section{Document license:}

CC BY-NC-ND

Please check the document version of this publication:

- A submitted manuscript is the version of the article upon submission and before peer-review. There can be important differences between the submitted version and the official published version of record. People interested in the research are advised to contact the author for the final version of the publication, or visit the DOI to the publisher's website.

- The final author version and the galley proof are versions of the publication after peer review.

- The final published version features the final layout of the paper including the volume, issue and page numbers.

Link to publication

\section{General rights}

Copyright and moral rights for the publications made accessible in the public portal are retained by the authors and/or other copyright owners and it is a condition of accessing publications that users recognise and abide by the legal requirements associated with these rights.

- Users may download and print one copy of any publication from the public portal for the purpose of private study or research.

- You may not further distribute the material or use it for any profit-making activity or commercial gain

- You may freely distribute the URL identifying the publication in the public portal.

If the publication is distributed under the terms of Article 25fa of the Dutch Copyright Act, indicated by the "Taverne" license above, please follow below link for the End User Agreement:

https://www.ou.nl/taverne-agreement

Take down policy

If you believe that this document breaches copyright please contact us at:

pure-support@ou.nl

providing details and we will investigate your claim.

Downloaded from https://research.ou.nl/ on date: 26 Apr. 2023 
Full length article

\title{
Playing style recognition through an adaptive video game
}

\author{
Boyan Bontchev*, Olga Georgieva \\ Faculty of Mathematics and Informatics, Sofia University, 5 James Bourchier Blvd., 1164, Sofia, Bulgaria
}

\section{A R T I C L E I N F O}

Article history:

Available online $\mathrm{xxx}$

Keywords

Playing style

Recognition

Adaptive game

Linear regression

\begin{abstract}
A B S T R A C T
Playing style recognition is crucially important for style-based adaptation of digital games. Unlike traditional ways for measuring of styles by means of self-reports, automatic style estimation incorporated into a video game appears to be a more efficient and ecologically valid method. The article presents a model for in-game recognition of four playing styles (Competitor, Dreamer, Logician, and Strategist) based on the Kolb's experiential learning theory. The model applies multiple linear regression over task performance metrics as explanatory variables and coefficients found first by a heuristic approach relaying on experience and observation knowledge of domain experts and, next, estimated by the least squares method. Experiments with the model implemented within an affectively adaptive video game demonstrated the benefits of emotion-based dynamic difficulty adjustment over playing outcomes and proved its validity as an accurate instrument for automatic estimation of both the four playing styles and the learning styles of Honey and Mumford.
\end{abstract}

\section{Introduction}

Human personality and player traits are important features of playing characters and offer, together with player's performance and emotional state, a solid groundwork for player-centric game adaptation (Yannakakis \& Paiva, 2014, pp. 459-471). Player-centric models allow designers to tailor gameplay to an individual with specific playing style determining player's needs, preferences and motivations (Magerko, Heeter, Fitzgerald, \& Medler, 2008). Adjusting various features of the game to playing types or styles can increase playing satisfaction and motivation (Birk, Toker, Mandryk, \& Conati, 2015), and efficacy of playing (Orji, Mandryk, Vassileva, \& Gerling, 2013). Like the game adaptation according to learning style, it can bring better learning outcomes (Soflano, Connolly, \& Hainey, 2015; Vassileva, 2012).

For achieving style-based adaptation in video gameplay, player's style should be recognized with an accuracy sufficient for the adaptation purposes. Static approaches for style estimation apply calculation of playing styles from self-report before entering the game (Birk et al., 2015; Magerko et al., 2008), whereupon the player is not aware of the process. In contrast to self-reports, automatic recognition of playing style during the play is much more promising, because it infers the style of the playing person by analyzing individual player interactions and achieved results. Automatic methods may categorize player's behavior including playing styles by means of self-organizing maps (Wong, Kim, Han, \& Jung, 2009), fuzzy cluster analysis and hidden Markov models (Etheredge, Lopes, \& Bidarra, 2013), or sev-

\footnotetext{
* Corresponding author.

Email addresses: bbontchev@fmi.uni-sofia.bg (B. Bontchev); o.georgieva@fmi. uni-sofia.bg (O. Georgieva)
}

eral classifiers (Cowley, Charles, Black, \& Hickey, 2013). They apply an analysis of player's behaviors at run time in an implicit way for the player and provide a basis for dynamic style-based adaptation of various features for both games for entertainment and applied games.

The present study aims at automatic in-game recognition of ADOPTA (ADaptive. technOlogy-enhanced Platform for eduTAinment) playing styles (Aleksieva-Petrova, Petrov, \& Bontchev, 2011) by using performance metrics of appropriate tasks in an adaptive video game. For improving player's experience and outcomes of task completion, gameplay difficulty was dynamically adapted based on both player's skills and manifested emotions inferred by analysis of still facial expressions (Bontchev, 2016). Playing styles were estimated by multiple linear regression applying as explanatory variables averaged normalized result (effectiveness) and time for achieving it, efficiency, normalized difficulty and effort, and other task completion metrics specific for each playing style. Regression coefficients were identified by structured interviews with game-based learning practitioners and, next, were estimated by the least squares method by comparing the estimated playing styles with results obtained by online administration of a playing style questionnaire. ADOPTA playing styles include Competitor, Dreamer, Logician, and Strategist. They are based on the Kolb's experiential learning theory (Kolb, 1984) and highly correlate with learning styles of Honey and Mumford (1992) because both have the same design base. Their correlations suppose the hypothesis that a model aimed at recognition of playing styles can be used for prediction of learning styles, as well. Thus, four main research questions (RQ) were identified here:

- RQ1: How an adaptive video game can implement a model for automatic recognition of playing styles based on multiple linear regression using performance metrics of game tasks related to specific style? 
- RQ2: What is the effect of affective adaptation of gameplay over performance metrics of game tasks used as explanatory variables for estimation of playing style?

- RQ3: What is the accuracy of in-game recognition of playing styles applying task performance metrics with parameters either quantified by expert evaluations or estimated by least squares?

- RQ4: How accurately the model for in-game recognition of playing styles can be used for prediction of learning styles?

The present work provides answers to the four research questions stated above. Its main contribution lies in the conceived model for an in-game recognition of the ADOPTA playing styles based on multiple linear regression over appropriate metrics of player performance related to a specific style and applied as explanatory variables. The practical experiments with an in-game implementation of the model proved that the multiple linear regression over task performance metrics appears to be an appropriate method for an ecologically valid automatic recognition of playing styles (RQ1). We found the affective adaptation mode brings statistically significant improvements in task effectiveness, efficiency and difficulty metrics (RQ2). Next, we discovered that the model with regression coefficients calculated by structured interviews can recognize playing style with less average accuracy $(71.19 \%)$ than that one with coefficients optimized by the least squares method using styles measured by a questionnaire as training dataset and having an average accuracy of $76.51 \%$ (RQ3). Finally, we found the average accuracy of Honey and Mumford's learning style prediction by the structured interviews regression model to be $79.50 \%$ and that of the least squares regression model to amount to $82.71 \%$ (RQ4). Thus, both the models for in-game recognition of playing styles can be used for an accurate prediction of learning styles.

The next section provides a description of previous works related to approaches for defining playing types and styles. It presents existing playing style families including styles based on the Kolb's experiential learning theory. Methods for calculation of styles from self-report are juxtaposed to automatic recognition of playing style during the game. Section 3 explains the model applying multiple linear regression for estimating ADOPTA playing style and its implementation within an adaptive video game named 'Rush for Gold'. The game contains shooting, discovering, puzzle solving and planning tasks adapted to both player's skills and emotions inferred by facial expressions. Section 4 outlines the experimental work concerning materials, procedure, and participants of two experiments: one intended to validate calculation of playing styles using regressions determined by structured interviews and to optimize them for playing in affectively adaptive mode, and another conducted to validate playing style recognition applying the optimized regression coefficients. Next section presents the beneficial effect of affective adaptation concerning player's outcomes and provides results and analysis of automatic recognition of playing styles, with an ability to predict learning styles, as well. The last three sections are dedicated to a discussion of achieved results, limitations of the study, and final concluding remarks.

\section{Background}

\subsection{Playing styles}

In last decades, various models of playing styles were proposed aiming to model "human personality in a game playing context" (Stewart, 2011). Playing style models have their origin in the oldest typology for play proposed by Caillois and including four different forms of playing behavior (Caillois \& Barash, 1961): Agon (games of competition), Alea (games of chance), Mimicry (role-playing games), and Ilinx (games inducing vertigo and other effects altering perception). Next, Malone (1981) defined a theory of intrinsically motivating instruction including three basic issues creating fun in digital games: challenge, extrinsic and intrinsic fantasy, and sensory and cognitive curiosity. Both the Caillois' forms of playing and the Malone's categories of challenge, fantasy, and curiosity serve as patterns of play. At the same time, they are closed to the Four Fun Keys of Lazzaro (2008) comprising hard fun (associated with challenges for achieving goals in the game), easy fun (linked to exploratory playful behavior), serious fun (related to playing for gaining rich gaming experiences while escaping from the real world), and people fun (originating from either collaborative or competitive play in multiplayer games). Altogether, these theories provided a basis for a further definition of playing types or styles.

Magerko et al. (2008) distinguished playing types (defined as persistent traits of the player) from playing styles treating "motivations as a more temporary state, with an implication that players may adopt different play styles in different games or at different times". Therefore, the playing style of an individual is to be defined concerning the context of given game type and for a particular period of time. Especially in the context of massively multiplayer online games, Richard Bartle (1996) coined four types of playing: killers (imposing themselves on other players by active and predominant play experience), achievers (collect game assets by overcoming gameplay challenges), explorers (eager to discover the game world), and socializers (making closer relationships with other players). Yee (2006) proposed a 40 items questionnaire based on Bartle's player types and related to player motivation, and administered it to more than three thousands of role-playing gamers. He found these playing styles have been not independent but correlated each other and recognized three main components of player motivation: achievement (incl. advancements, mechanics, and competition); social component (incl. socializing, relationships, and teamwork); and immersion (incl. discovery, role-playing, and customization). Next, Klawe (1999) reported two playing types adopted by children while playing educational computer game: some pursue a fast win in the game, while others are more inclined in exploring the game world. Heeter and Winn (2008) explored playing styles based on the speed of play (committing many mistakes versus trying to avoid mistakes) and success in problem-solving (achievers versus explorers), within educational game context. Magerko et al. (2008) supposed that both achievement-oriented and performance-avoidance (trying to avoid failure instead to seek success) playing styles are about an extrinsically motivated gameplay, while explorers and immersion players suppose intrinsically motivated gameplay.

In contrast with the modeling approaches outlined over and dedicated to a specific game type context, other playing style typologies were proposed based on psychometric approaches to personality assessment. The first demographic game design (DGD1) player typology was suggested by Bateman and Boon (2005) as a derivation from Myers-Briggs typology and Jung's temperament theory. It describes four, non-orthogonal player's types and gameplay preferences associated to them: conquerors (very competitive and dominant goal-oriented players eager to win), managers (process-oriented players enjoying enhancing and practicing their mastery), wanderers (looking for enjoyment and rich experiences), and participants (interested in social interactions). Nest to DGD1, a second demographic game design (DGD2) player model was conceived related to the Temperament theory and containing logistical, tactical, strategic, and diplomatic player types (Bateman, Lowenhaupt, \& Nacke, 2011). Recently, the BrainHex model was suggested by Nacke, Bateman, and Mandryk (2013) with aiming at a typology of playing preferences 
combining findings from demographic game design with neurobiological factors and containing archetypes of a particular player experience, such as seekers, survivals, daredevils, masterminds, conquerors, socializers, and achievers. Stewart (2011) proposed a unified model of personality and play styles regarding the four Keirsey's temperaments (Keirsey, 1998) as supersets of the Bartle's styles.

The present study aims at an automatic, in-game recognition of playing styles based on the Kolb's experiential learning theory, which at the same time provides the opportunity to predict the learning style of the player.

\subsection{Playing styles based on the Kolb's experiential learning theory}

While discussing playing style with regard to motivation, Magerko et al. (2008) view motivation as "a central correlate to learning", which makes a parallel between playing and learning styles. Curry (1981) defined learning style as "characteristic cognitive, effective, and psychosocial behaviors that serve as relatively stable indicators of how learners perceive, interact with, and respond to the learning environment". The integrated process of comprehension, interaction, and response to the learning environment was generalized by Kolb (1984) as a creation of knowledge through a transformation of experience. The Kolb's experiential learning theory defines a four stages cycle of effective learning involving individual progress from (1) concrete experience (CE), followed by (2) reflective observation (RO), resulting in (3) abstract conceptualization (AC), giving rise to (4) active experimentation (AE). Based on this transformation of experience, Kolb defines his Learning Style Inventory over two-dimensional space with a Processing Continuum over the horizontal axis and a Perception Continuum over the vertical axis. It including four learning styles: accommodator (from $\mathrm{AE}$ to $\mathrm{CE}$ ), diverger (from $\mathrm{CE}$ to $\mathrm{RO}$ ), assimilator (from $\mathrm{RO}$ to $\mathrm{AC}$ ), and converger (from $\mathrm{AC}$ to $\mathrm{AE}$ ).

On the top of the Kolb's Learning Style Inventory, Honey and Mumford (1992) built their Learning Style Questionnaire (LSQ), which involves four distinct styles of learning: activists (learning by experience), reflectors (learning from reflective observations), theorists (learning from analyzing interrelationships), and pragmatics (learning from acting and aiming at practical outcomes). In a similar way, Aleksieva-Petrova et al. (2011) applied the Kolb's space of processing and perception continuums as a two-dimensional basis for defining four styles but in a different context - that of playing games. They created the ADOPTA family of playing styles especially for run-time control of decision making in educational games similarly to dynamic adaptation of courseware delivery. ADOPTA includes four playing styles as follows:

- Competitors - players relying mostly on their intuition and taking great risks that seem to them reasonable; skilled in fast problem-solving by trial and error methods; good in critical situations during game requiring preservation of composure and self-control; prefer to start active playing as soon as possible; outlined by the others as the most active players.

- Dreamers - players preferring to observe the play instead to control it; like guided gameplay and staying at given game level until mastering it sufficiently; need to see different perspectives about game missions and to consider them carefully; open-hearted about their feelings; prefer to observe and to listen to the arguments of the others; fond of social interaction, diplomacy and negotiation; like playing with clear game scenarios instead emergent gameplay.

- Logicians - like logic, analyses and pattern-based approaches for task completion; possess good spatial awareness and contextual thinking; learn the intricacies of each game rule and apply them for each move in a rational and perfect way; assemble the facts into a coherent rational scheme useful for further synthesis of game tactics and strategies; do not trust directly arguments and assumptions of the others; try to establish and impose rational, structural time-based approaches; converge existing opinions and ideas in a logical and uncontroversial way.

- Strategists - like resolving complex problems within a game in a most effective way; try to find practical ways to fulfil the game tasks on time; seek opportunities to apply them for reaching practical outcomes; have long-term thinking when planning their strategies and like decision-making, testing hypotheses, and seeing the practical consequences of their experiments and actions taken; never betray their realism and have good management skills.

The four playing styles are presented in Fig. 1 together with the defined of Honey and Mumford's learning styles of Reflector, Theorist, Activist, and Pragmatist, on the top of the Kolb's Learning Style Inventory. Table 1 defines the mapping between Honey and Mumford's learning styles and playing styles of ADOPTA and Bartle.

ADOPTA playing styles, together with Honey and Mumford's learning styles were used for dynamic selection of learning objects in an adaptive game-based learning (Vassileva, 2012). Next, a playing style questionnaire (ADOPTA PSQ) with 40 dichotomous items about the ADOPTA playing styles was administered to 260 subjects and was proven for having acceptable validity (Cronbach's alpha averaged for all the styles equal to 0.73289 ) and good test-retest reliability. However, both playing and learning styles should be recognized in an ecological and more efficient way than by means of ques-

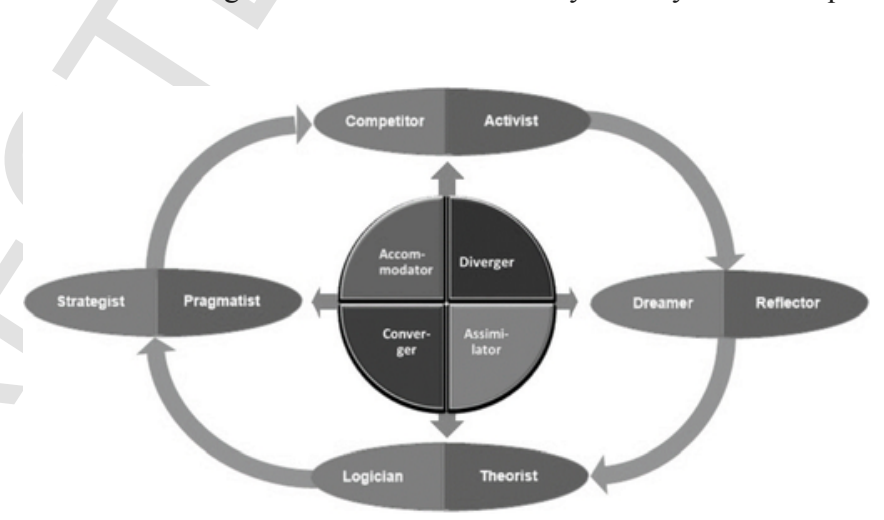

Fig. 1. The four ADOPTA playing styles together with the learning styles of Honey and Mumford and of Kolb.

Table 1

Relationships between Honey and Mumford's learning styles and playing styles of ADOPTA and Bartle.

\begin{tabular}{|c|c|c|c|}
\hline $\begin{array}{l}\text { Honey and } \\
\text { Mumford }\end{array}$ & Learns by & ADOPTA & Bartle \\
\hline Activist & $\begin{array}{l}\text { hand-eye coordination, planning and } \\
\text { strategizing, problem-solving, teamwork, } \\
\text { with ability to think quickly }\end{array}$ & Competitor & Killer \\
\hline Theorist & $\begin{array}{l}\text { logically entering problems step-by-step, } \\
\text { with spatial awareness plus verbal and } \\
\text { numeracy skills }\end{array}$ & Logician & Explorer \\
\hline Pragmatist & $\begin{array}{l}\text { planning, decision-making, testing } \\
\text { hypotheses, strategic thinking, } \\
\text { management tasks }\end{array}$ & Strategist & Achiever \\
\hline Reflector & $\begin{array}{l}\text { observing and listening to the arguments of } \\
\text { the others in social interactions based on } \\
\text { diplomacy and negotiation }\end{array}$ & Dreamer & Socializer \\
\hline
\end{tabular}


tionnaires, such as within the process of playing a game or studying a subject.

\subsection{Recognition of playing styles}

Accurate and efficient recognition of playing styles is crucially important for creating digital games with style-based adaptation. For finding the playing style of an individual player, two types of approaches can be undertaken:

1. Measurement of playing styles by means of self-report data - the player has to fill in a pre-game questionnaire and his/her playing style will be calculated before entering the game (Birk et al., 2015; Magerko et al., 2008).

2. Automatic recognition of playing style during the play - the game can infer the style of the playing person by analyzing individual player's interactions and achieved results.

The first approach requires additional time to complete the questionnaire and suffers from possibly subjective self-assessment of the player. Magerko et al. (2008) designed a learning mini-game with intelligently adapted gameplay according to learning style of individual players. Authors identified and adapted six game features to intrinsically motivated explorers, extrinsically motivated performance-approaching achievers, and extrinsically motivated loss-avoiding winners. Individual playing type was determined by a questionnaire and was used to assign adaptable game features to the player of this type. Recently, multiple linear regression was applied to reveal how personality and player traits in an ecologically valid video game context moderate the established link between need satisfaction and motivation (Birk et al., 2015). Authors assessed player-centric and personality traits with surveying players by several questionnaires with validated scale.

The advantage of the second approach - addressed by the current study - consists in the implicit recognition of styles, whereupon the player is not aware of the process. Wong et al. (2009) applied a self-organizing map to categorize similar player's behaviors in real time. By means of unsupervised clustering, they grouped data about player's styles and used it for a non-invasive game adaptation. Etheredge et al. (2013) applied fuzzy cluster analysis and a hidden Markov model for classifying players' behavior in any type of adaptive games. Their method is generic, because it is focused neither on a specific family of playing styles nor on a fixed game type. Cowley et al. (2013) suggested automatic classification of DGD player types in the context of playing the Pac-Man game. Authors determined DGD type of each individual player by administrating the DGD questionnaire and, next, found and monitored game metrics and features relevant to specific behavioral traits in order to use gained training data for machine learning in real time with several classifiers for dichotomous classification (e.g., manager or not manager), with a maximal accuracy of $72 \%$.

Thus, the approach for automatic classification of player behavior by analyzing individual player's interactions during the game has been implemented by automatic classification of game metrics and features relevant to specific behavioral traits. The present study applies run time linear regression calculation of playing styles using metrics of player's behavior in a game context, in order to achieve a novel, accurate in-game recognition of playing styles, together with prediction of learning styles.

\subsection{Linear regression used for game adaptation}

Simple linear regression represents an approach for modeling linear relationship between a dependent variable and one independent (explanatory) variable (Freedman, 2009, p. 26). In case of more than one explanatory variable, the model is called multiple linear regression. It presents the dependency in the form of a linear predictor function described as:

$$
\mathrm{y}=\mathrm{q}_{1} \mathrm{x}_{1}+\mathrm{q}_{2} \mathrm{x}_{2}+\ldots+\mathrm{q}_{\mathrm{M}} \mathrm{x}_{\mathrm{M}}+\mathrm{q}_{\mathrm{M}+1}
$$

where $\mathrm{y}$ is dependent variable, and $\mathrm{x}_{\mathrm{k}}(\mathrm{k}=1 \div \mathrm{M})$ are independent variables. The vector of the regression coefficients including a free term (intercept) $\mathrm{Q}=\left[\mathrm{q}_{1}, \mathrm{q}_{2}, \ldots, \mathrm{q}_{\mathrm{M}}, \mathrm{q}_{\mathrm{M}+1}\right]$ determines the regression slope.

The equation (1) should cover with minimal error data accumulated for different subjects. Thus, the model (1) is described in a matrix form as:

$$
\mathrm{Y}=\mathrm{Q} \mathrm{X}
$$

where $\mathrm{Y}=\left[\mathrm{y}_{1}, \mathrm{y}_{2}, \ldots, \mathrm{y}_{\mathrm{N}}\right]^{\mathrm{T}}$ is a data vector of the values of dependent variable, $\mathrm{X}$ is $\mathrm{N} x \mathrm{M}$ data matrix of explanatory variables values, where $\mathrm{N}$ is the number of the data in the data set that corresponds to the number of game players and $\mathrm{M}$ is the number of independent model variables. Generally, there are two possible ways to determine the unknown vector $Q$. The first one is a fully heuristic approach that relays on existing experience and observation knowledge of domain experts. The other approach applies an optimization procedure to the matrix equation (2). For this purpose, a training data set used and the model have to be investigated to predict the validation data set. Both the approaches for estimation of the unknown model coefficients were investigated in this research.

In affectively adaptive games, linear regression was applied as a method for estimating player's emotions based on physiological measurements (Novak, Mihelj, \& Munih, 2012). Toups et al. (2006) employed linear regression with measurements of electrodermal activity (EDA) and electromyography as independent variables to adjust game mechanics by means of manually set regression coefficients. Fairclough and Venables (2006) applied multiple regression analyses based on various psychophysiological explanatory variables, for predicting variance of task engagement and distress produced by solving computer tasks. Fairclough and Gilleade (2012) adjusted the speed of falling Tetris blocks according to player's boredom, engagement, and overload estimated linearly by means of electroencephalographic measures. Nogueira, Rodrigues, and Oliveira (2013) used player's arousal and emotional valence as dependent variable and skin conductance, heart rate, and facial electromyography as explanatory variables for physiological emotion recognition. They employed the normalized residual sum of squares as a relative indicator of the model's error to merge various regression outputs in real-time and reported accuracy ratings of $85 \%$ for arousal and $78 \%$ for valence.

All the approaches cited over applied linear regression for estimation of player's affect based on physiological features. In contrast with them, the present work uses the same method for estimation of other player's characteristics - namely the playing style - by using appropriate gameplay metrics. 


\section{Video game for recognition of playing styles}

\subsection{Data model development}

The present data model applies multiple linear regression for estimating ADOPTA playing styles described in section 2.2. In equation (2), we denote $X_{i}$ as a data matrix formed by values of appropriate gameplay metrics (explanatory variables) collected during the game sessions of different players, and $\mathrm{Y}_{\mathrm{i}}$ as a data vector of the respective style measured by self-report using ADOPTA PSQ. Note that here the index $\mathrm{i}=[\mathrm{C}, \mathrm{D}, \mathrm{L}, \mathrm{S}]$ includes the four playing styles - Competitor, Dreamer, Logician, and Strategist, as four different models are to be established.

At the model development stage, the explanatory (independent) variables are to be identified according to the specifics of each ADOPTA playing style. For this purpose, discussions and semi-structured qualitative interviews (Edwards \& Holland, 2013) were carried out with seven game-based learning practitioners. In the course of the discussions, it was clarified that all the playing styles can be estimated through key performance indicators of game tasks corresponding to each one style, including task result (effect), task efficiency (ratio between performance and particular effort), and task difficulty. While efficiency varies from 0 to 1 , result and difficulty of task execution should be normalized for having values in the range of $[0,1]$. Thus, there were identified three explanatory variables, as follows:

- Average normalized total result (effectiveness) in \%: $\mathrm{R}_{\text {norm }}=\mathrm{N}_{\text {collected }} / 12$ (collected bars of gold for all the task divided to the maximal possible number of bars of gold)

- Average efficiency in \%: AE (ratio between number of solved tasks and number of all trials to solve the tasks)

- Average normalized difficulty in \%: $\mathrm{AD}_{\text {norm }}$ (average difficulty for all performed tasks of given type divided to the maximal possible difficulty for these tasks)

By means of these explanatory variables and applying equation (1), the estimation for the first three playing style is:

\section{? Competitor:}

$\mathrm{R}_{\mathrm{C}}=\mathrm{Q}_{\mathrm{C} 1} * \mathrm{R}_{\mathrm{Cnorm}}+\mathrm{Q}_{\mathrm{C} 2} * \mathrm{AE}_{\mathrm{C}}+\mathrm{Q}_{\mathrm{C} 3} * \mathrm{AD}_{\mathrm{Cnorm}}+\mathrm{Q}_{\mathrm{C} 4}$

? Dreamer: $\mathrm{R}_{\mathrm{D}}=\mathrm{Q}_{\mathrm{D} 1} * \mathrm{R}_{\mathrm{Dnorm}}+\mathrm{Q}_{\mathrm{D} 2}{ }^{*} \mathrm{AE}_{\mathrm{D}}+\mathrm{Q}_{\mathrm{D} 3} * \mathrm{AD}_{\text {Dnorm }}+\mathrm{Q}_{\mathrm{D} 4}$

? Logician: $\mathrm{R}_{\mathrm{L}}=\mathrm{Q}_{\mathrm{L} 1} * \mathrm{R}_{\mathrm{Lnorm}}+\mathrm{Q}_{\mathrm{L} 2} * \mathrm{AE}_{\mathrm{L}}+\mathrm{Q}_{\mathrm{L} 3} * \mathrm{AD}_{\mathrm{Lnorm}}+\mathrm{Q}_{\mathrm{L} 4}$

For estimating the Competitor, Dreamer, and Logician style, attracting and easy game tasks can be simply conceived, for example, as tasks of shooting, discovering, and puzzle solving type. However, game tasks for Strategists require strategic vision and both effective and efficient decision-making throughout the overall game session. Therefore, the Strategist style appeared to depend on average time effectiveness and efficiency, normalized difficulty and normalized effort for all type of tasks. As well, the Strategist style is dependent on the normalized numbers of both planning and monitoring events. Hence, for this style we have to account the following explanatory variables:

- Relative normalized time for achieved overall result: $\mathrm{T}_{\mathrm{REL}}=(\mathrm{SES}-$ SION_TIME_MAX + SESSION_TIME_MIN - session time)/SESSION_TIME_MAX ${ }^{*} \mathrm{R}_{\text {norm }}$

- Average efficiency for all the shooting/discovering/solving tasks in $\%: \mathrm{AE}_{\mathrm{ALL}}$

- Average normalized difficulty for all the shooting/discovering/solving tasks in \%: $\mathrm{AD}_{\mathrm{ALLnorm}}$
- Normalized number of planning events (changes in strategic planning divided to the maximal number of changes): $\mathrm{N}_{\text {PLANnorm }}=\mathrm{N}_{\text {PLANchanges }} / \mathrm{N}_{\text {PLANchanges_max }}$

- Normalized number of plan checking events (checks of strategic planning divided to the maximal number of checks): $\mathrm{N}_{\text {CHECKnorm }}=\mathrm{N}_{\text {PLANchecks }} / \mathrm{N}_{\text {PLANchecks max }}$

- Average normalized effort for all the shooting/discovering/solving tasks in \%: $\mathrm{AEFF}_{\mathrm{ALLnorm}}=\left(\mathrm{N}_{\text {trialsC }}+\mathrm{N}_{\text {trialsD }}+\mathrm{N}_{\text {trialsL }}\right) / 3 / \mathrm{AEFF}_{\max }$

Thus, the strategic playing style can be estimated according to equation (1) by six independent variables:

? Strate-

gist: $\mathrm{R}_{\mathrm{S}}=\mathrm{Q}_{\mathrm{S} 1}{ }^{*} \mathrm{~T}_{\mathrm{REL}}+\mathrm{Q}_{\mathrm{S} 2}{ }^{*} \mathrm{AE}_{\mathrm{ALL}}+\mathrm{Q}_{\mathrm{S} 3}{ }^{*} \mathrm{AD}_{\mathrm{ALL}}+\mathrm{Q}_{\mathrm{S} 4}{ }^{*} \mathrm{~N}_{\mathrm{PLANnorm}}+\mathrm{Q}_{\mathrm{S} 5}$

\subsection{Gameplay design}

For practical estimation of the playing styles outlined over by multiple linear regression using key performance indicators of game tasks, the 'Rush for Gold' action video game was created. For estimating the Competitor, Dreamer, and Logician style, the game contains shooting, discovering, and puzzle solving tasks. All the tasks aim explicitly at collecting of gold bars in an Egyptian temple. Each task challenges knowledge and intellectual abilities of the player according to a specific playing style. Shooting tasks require hitting and collecting at least two and no more than six of the gold bars flying near the ceiling of the temple (Fig. 2). Tasks for discovering imply finding gold bars hidden at secret places at the temple, while the third group of tasks requires solving logic puzzles for receiving gold bullions.

Besides these explicit tasks, 'Rush for Gold' includes also some implicit tasks, such doing strategic planning and monitoring of playing activities by means of a Strategy Management Table (SMT). As shown in Fig. 2, SMT provides three rows for planning number of gold bars for the explicit tasks. As well, SMT reports average efficiency (AE) of task performance of tasks as a ratio between hit bars and total number of shots (for shooting tasks); found bars divided by number of passes near hidden gold bullions until finding and collecting them (for discovering tasks); and number of right answers divided by total number of answers tried by the player (for solving tasks). Both SMT planning and monitoring are not mandatory but participate as explanatory variables in linear regression for estimating the Strategist style.

In order to improve player's experience and outcomes of task completion, affective adjustment of gameplay was applied together with performance-based adaptation. The affectively adapted version of the 'Rush for Gold' game uses dynamic difficulty adjustment (DDA) according to player's emotions (Chang, 2013) inferred by analysis of still facial expressions (Bontchev, 2016). According to both player's skill acquisition and inferred emotions, the method of DDA adapts dynamically level of task difficulty applying linear regressions with specific threshold values (Bontchev \& Vassileva, 2016) in a way similar to the approaches outlined in section 2.4. With the increase of player's positive emotions, hidden bars of gold appear are moved to more hidden places in order to be more difficult for discovering. As well, when affectation level becomes higher, flying gold bullions change their velocity and acceleration set initially according to player's performance. In contrast to shooting and discovering tasks, puzzle solving tasks apply affect-based adaptation statically, i.e. only when selecting new puzzle to be shown in the game, because replac- 


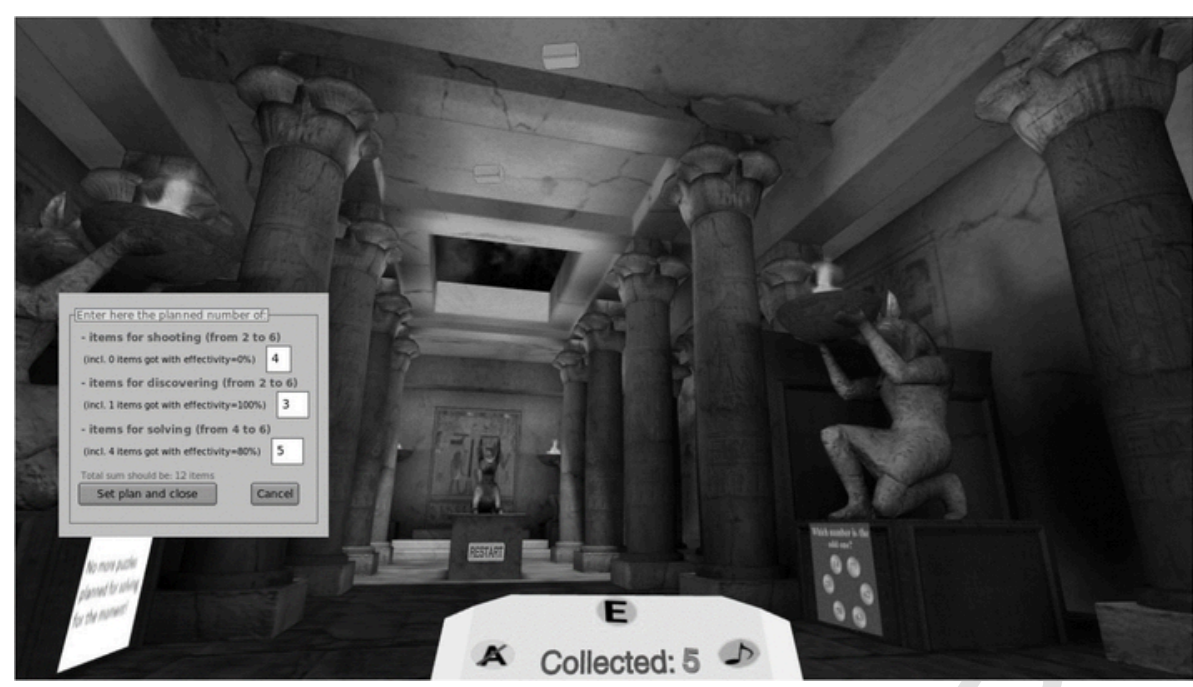

Fig. 2. A view of the 'Rush for Gold' game with shown SMT.

ing shown puzzle by another with different difficulty would embarrass the player.

\section{Experimental work}

Two practical experiments with the 'Rush for Gold' game were conducted. The purpose of the first experiment was to determine the model for in-game calculation of playing styles using regression coefficients found by structured interviews with experts and, next, to optimize the model for playing in affectively adaptive mode. The second experiment aimed at validation of the optimized coefficients and the effect of affective adaptation on player's outcomes by playing the same adaptive video game.

\subsection{Materials}

For conducting both the experiments, an experimental setup was assembled on a single gamer laptop with 15" LCD using a Logitech wireless mouse and the custom EDA measuring device. The software included an affectively adapted version of 'Rush for Gold' video game with both performance-based and affective adaptation of game tasks and visual effects as described in (Bontchev \& Vassileva, 2016). Player's emotions were inferred by both EDA signal and still face expressions in a time window of $10 \mathrm{~s}$ (Bontchev, 2016). 'Rush for Gold' was applied for automatic recognition of playing and learning styles, which were communicated to an educational maze game with leaning content about strategic business management adapted to the recognized individual style. Both 'Rush for Gold' and the maze video game were developed by means of the Brainstorm eStudio platform ${ }^{1}$ using music, textures and $3 \mathrm{D}$ visual objects specially designed for this purpose.

For each participant, the playing style recognized implicitly during the game was compared to self-reported styles calculated by administering online two 40 items questionnaires: Honey and Mumford's learning style questionnaire (LSQ) and ADOPTA PSQ.

\footnotetext{
${ }^{1}$ http://www.brainstorm.es/products/estudio/.
}

\subsection{Procedure}

The experimental procedure consisted of a selection of volunteers for participation in the experiment, gaming sessions' appointment, individual explanation and demonstration, informed consent procedure, game sessions, and post-game self-reporting by filling online a joint questionnaire. Each individual participant signed a consent form (translated in Bulgarian). Next, for calibration of the EDA measuring device, he/she was asked to spend $2 \mathrm{~min}$ in relaxation with electrodes placed at the middle and ring fingers, while listening to calm music and watching playing instructions. Thereafter, the player performed a short assisted training session playing 'Rush for Gold' followed by two game sessions in random order - one without and another with affective adaptation control, without imposing any time constraints. No background music was played during the sessions other than game music and shooting and hitting event-related sounds.

After all gaming sessions, each player was asked to fill in an online compound questionnaire containing a player demography section, questions about previous gaming experience and amount of video gameplay, ADOPTA 40 items PSQ, and questions about affective game adaptation. For the first experiment, Honey and Mumford's 40 items LSQ was included, as well. In the end, the participant was asked to share his/her personal impressions of all the phases of the experiment.

\subsection{Participants}

Both the practical experiments with the 'Rush for Gold' games were conducted at the Faculty of Mathematics and Informatics at Sofia University, Bulgaria. For the first experiment (aimed at model determination), there were selected 34 volunteers among students and lecturers in informatics (age statistics: $\mathrm{M}=26.85, \mathrm{SD}=10.48$; gender balance: 18 men and 16 women). $76 \%$ of them had previous gaming experience on an average of $2-3 \mathrm{~h}$ per week. About $60 \%$ of all participants reported to play up to $10 \mathrm{~h}$ per game on average and, as well, no more than 3 games per year.

30 volunteers took part in the second experiment used for model validation (age statistics: $\mathrm{M}=31.87, \mathrm{SD}=10.05$; gender balance: 18 men and 12 women). $90 \%$ of them are experienced in gaming, but 
taking mostly several hours per week. As for the first experiments, the majority of the participants appeared to be moderate players.

\section{Results and analysis}

\subsection{Model identification}

For identifying preliminary values of the correlation coefficients $\mathrm{Q}_{\mathrm{k}}$, a qualitative study applying structured interviews (SI) was carried out (Edwards \& Holland, 2013) with seven game-based learning practitioners. For the Competitor, Dreamer, and Logician playing styles all interviewees agree on coefficients $\mathrm{Q}_{1}=40 \%, \mathrm{Q}_{2}=30 \%$, and $\mathrm{Q}_{3}=40 \%$. However, they had different visions about the assessment of the Strategist style and, thus, suggested different values for coefficients $\mathrm{Q}_{1} \div \mathrm{Q}_{6}$ for Strategist. Therefore, mean values for $\mathrm{Q}_{1} \div \mathrm{Q}_{6}$ were applied for the game-based playing style estimation. The left part of Table 2 presents all the coefficients of the multiple linear regression models found by structured interviews. The coefficients $\mathrm{Q}_{1} \div \mathrm{Q}_{6}$ used for estimating Strategist are given as mean values followed by respective standard deviation given in brackets. The free coefficients (intercepts) for the model determined by structured interviews $\left(Q_{4}\right.$ for the first three styles and $\mathrm{Q}_{7}$ for Strategist) were found as a difference between the mean of the estimated values and the mean of the styles calculated by administrating the ADOPTA PSQ to 34 subjects.

Next, linear regression coefficients were estimated by the least squares (LS) method (van de Geer, 2001) using playing styles values found by ADOPTA PSQ. The linear least squares method applied for the matrix equation (2) estimates the respective coefficients vectors $\mathrm{Q}_{\mathrm{i}}$ by the formula:

$$
\mathrm{Qi}=\left(\mathrm{Xi}^{\mathrm{T}} * \mathrm{Xi}\right)^{-1} * \mathrm{Xi}^{\mathrm{T}} * \mathrm{Y}_{\mathrm{i}}^{\text {training }}
$$

The training dataset denoted as $\mathrm{Y}_{\mathrm{i}}^{\text {training }}$ represents results obtained by ADOPTA PSQ. For the model identification experiment, the vector $Y_{i}^{\text {training }}$ is of size $N=34$ and the matrix $X_{i}$ has a size $34 \times 4$ for the Competitor, Dreamer, Logician styles, and $34 \times 7$ for Strategist.

The right part of Table 2 presents the linear regression coefficients estimated by the LS method using playing styles measured by ADOPTA PSQ. Both the linear regression coefficients found by SI and optimized by LS were applied next for recognition of playing and learning styles.

After determining linear regression coefficients by means of both SI and LS methods, we studied the effect of affective gameplay adaptation on performance metrics of game tasks used as explanatory variables (vector $\mathrm{X}_{\mathrm{i}}$ ) for estimation of each playing style, whereupon the estimated style is compared to the style measured by ADOPTA PSQ (vector $\mathrm{Y}_{\mathrm{i}}$ for $\mathrm{i}=[\mathrm{C}, \mathrm{D}, \mathrm{L}, \mathrm{S}]$ ). We compared these performance metrics obtained from game playing session without and with affective adaptation control. Table 3 presents relative improvements in effectiveness, efficiency, and difficulty of shooting, discovering and solving tasks thanks to the affective adaptation of gameplay. For each type of task, the relative improvement is calculated as mean of differences between the metric in adaptive and non-adaptive mode divided to the metric value in non-adaptive mode. Paired two-tailed T-tests for metrics of shooting, discovering and puzzle solving task show statistically significant improvements (given in bold in the table) only for efficiency and difficulty of both shooting and discovering tasks, for the effectiveness of discovering and for puzzle solving efficiency. Cohen $d$ values indicating the standardized difference between their means confirms an effect size between small and median (Rosenthal, 1996). The relative improvement in efficiency and difficulty can be explained by the positive effect of affect-based DDA on task performance, whereupon hard tasks become easier with manifested negative emotions (sadness, fear, anger, or disgust) and vice versa. The effectiveness of discovering tasks improves in adaptive mode because hidden gold bars become easier for finding when the player looks for them a long time and displays a higher negative affect. The same considerations are valid for the relative improvements found in metrics for the Strategist style (Table 4). While average efficiency and difficulty are increased in affective adaptation mode at a level of significance $p<.01$ and with medium effect size, the average effort is strongly decreased with at a level of significance $p<.0000$ and with very large effect size (Rosenthal, 1996). Although session time is decreased due to affective adaptation, relative time was found to be higher because it depends linearly on the normalized total result. The processes of planning and monitoring the plan are not significantly improved by the affective adaptation because both they do not depend on it.

Fig. 3 represents box plots of playing styles estimated with regression coefficients found by structured interviews and least squares. For each of the first three styles, the couples of box plots have similar medians, interquartile ranges (IQRs), whiskers and, for Dreamer and Logician, outliers. The box plots of Strategists estimated by SI and LS have some differences, however, with very small effect size - Cohen's $d$ appears to be 0.00028 .

The accuracy of the multiple linear regression models with coefficients found by SI and LS methods was estimated using several statistics. Table 5 present maximal absolute error as the maximal absolute difference between estimated percent value and reported percent value for the style and root mean square error (RMSE), together with correlations of estimated with reported values for all the four styles. Pearson $r$ shows high and statistically significant correlations $(p<.0000)$. Next, the table presents calculated values of $r^{2}$ (coefficient of determination) and adjusted $r^{2}$ providing a measure of the global fit of the models. According to the values of adjusted $r^{2}$, the unexplained variance of the Strategist model is higher than one of the other models. On the other hand, for Strategists estimated by six ex-

Table 2

Coefficients of multiple linear regression models found by structured interviews and least squares method.

\begin{tabular}{|c|c|c|c|c|c|c|c|c|}
\hline \multirow[t]{2}{*}{ Model Coeff. } & \multicolumn{4}{|c|}{ Structured Interviews } & \multicolumn{4}{|c|}{ Least Squares } \\
\hline & Competitor & Dreamer & Logician & Strategist & Competitor & Dreamer & Logician & Strategist \\
\hline $\mathrm{Q}_{1}$ & 40 & 40 & 40 & $31.5714(3,3320)$ & 52.1160 & 38.3904 & 38.1276 & 34.3494 \\
\hline $\mathrm{Q}_{2}$ & 30 & 30 & 30 & $19.5714(0,7284)$ & 41.3919 & 46.7008 & 31.7610 & 31.9130 \\
\hline $\mathrm{Q}_{3}$ & 30 & 30 & 30 & $32.1428(2,6954)$ & 12.6015 & 14.2393 & 41.3875 & 55.0562 \\
\hline $\mathrm{Q}_{4}$ & 4.7008 & 6.8378 & 1.5480 & $4.7142(0,4518)$ & -0.6350 & -7.2846 & -8.7434 & 4.1748 \\
\hline $\mathrm{Q}_{5}$ & & & & $3.8571(0,9897)$ & & & & 4.3702 \\
\hline $\mathrm{Q}_{6}$ & & & & $8.1428(0,3499)$ & & & & 16.7511 \\
\hline $\mathrm{Q}_{7}$ & & & & -5.3133 & & & & -26.3698 \\
\hline
\end{tabular}


Table 3

Relative improvements in task effectiveness, efficiency and difficulty due to affective adaptation.

\begin{tabular}{llll}
\hline Statistic & \multicolumn{2}{l}{ Metrics of shooting, discovering and solving tasks } \\
\hline & Effectiveness & Efficiency & Difficulty \\
\hline Shooting task improvement & $7.56 \%$ & $\mathbf{1 6 . 8 9 \%}$ & $\mathbf{6 . 1 9 \%}$ \\
$p$ & 0.0832 & 0.0104 & 0.0351 \\
$d$ & 0.2293 & 0.3025 & 0.2356 \\
Discovering task improvement & $\mathbf{9 . 0 9 \%}$ & $\mathbf{8 . 6 1 \%}$ & $\mathbf{4 . 4 5 \%}$ \\
$p$ & 0.0194 & 0.0017 & 0.0185 \\
$d$ & 0.3999 & 0.3337 & 0.3422 \\
Solving task improvement & $6.08 \%$ & $\mathbf{2 1 . 1 2 \%}$ & $2.64 \%$ \\
$p$ & 0.0831 & 0.0054 & 0.1775 \\
$d$ & 0.2414 & 0.3149 & 0.1631 \\
\hline
\end{tabular}

Table 4

Relative improvements in metrics for the Strategist style.

\begin{tabular}{lllllll}
\hline Statistic & \multicolumn{2}{l}{ Metrics for the Strategist style } & & & \\
\hline & $\begin{array}{l}\text { Relative } \\
\text { time }\end{array}$ & $\begin{array}{l}\text { Average } \\
\text { efficiency }\end{array}$ & $\begin{array}{l}\text { Average } \\
\text { difficulty }\end{array}$ & Plans & $\begin{array}{l}\text { Plan } \\
\text { checks }\end{array}$ & $\begin{array}{l}\text { Average } \\
\text { effort }\end{array}$ \\
\hline $\begin{array}{l}\text { Increase } \\
(\%)\end{array}$ & $\mathbf{8 . 4 6}$ & $\mathbf{1 4 . 6 5}$ & $\mathbf{4 . 7 6}$ & 7.32 & 2.04 & $\mathbf{- 5 1 . 8 1}$ \\
$p$ & 0.0000 & 0.0000 & 0.0013 & 0.3246 & 0.6614 & 0.0000 \\
$d$ & 0.3858 & 0.4656 & 0.4386 & 0.1003 & 0.0284 & -1.2690 \\
\hline
\end{tabular}

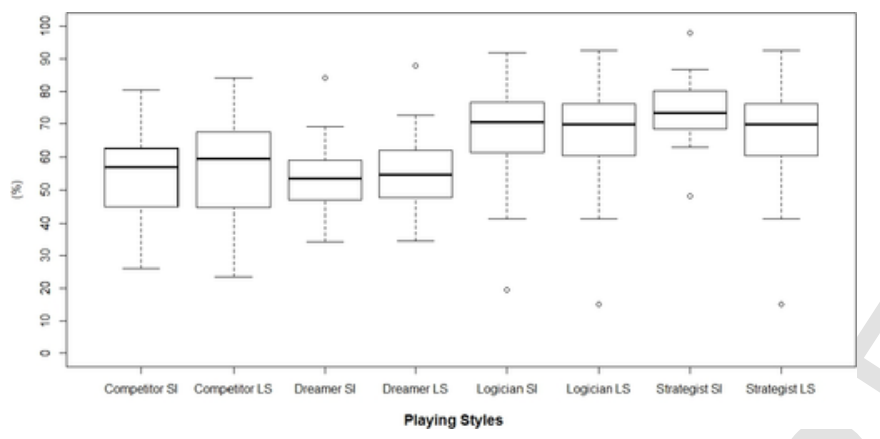

Fig. 3. Playing styles estimated with regression coefficients found by structured interviews (SI) and least squares (LS).

planatory variables, we received a worse global fit: Pearson $r=0.6432$, $r^{2}=0.4137$, and adjusted $r^{2}=0.3090$.

It is interesting to point out that the proposals of game-based learning practitioners are not too far from the optimal regression coefficients found by the LS method. We performed Student's two-tailed paired T-test and received statistically significant differences of means for Dreamer and Logician (Table 6), however, the effect size of the difference of mean values is very small $(d<0.20)$. Therefore, both the methods enable to grasp the dependency between the metrics and corresponding style in a simple and intuitive way.

Figs. 4-7 illustrate the obtained model results respectively for the Competitor, Dreamer, Logician, and Strategist style. The first image of each figure presents the absolute errors calculated for each subject as a difference between questionnaire data and respective model value. The second figure of each style shows the estimated results by both LS and SI models against the PSQ survey data.

Table 7 presents correlations of reported playing styles (measured by the ADOPTA PSQ) with learning styles (measured by the Honey and Mumford's LSQ) together with calculated effect size (Cohen's $d$ ). As expected, playing styles are highly correlated with learning styles (with $p$-values less than 0.00005), which can be explained by the fact both they are based on the Kolb's experiential learning theory.

Thanks to the high correlation between ADOPTA playing styles and learning styles of Honey and Mumford, we can expect that linear regressions for playing style estimation are able to predict learning styles, as well. This is crucially important for style-based adaptation in educational games. Table 8 presents statistics about the prediction of learning style by the playing style calculated through linear regressions using SI and LS coefficients. In contrast with estimation of playing styles, here the regressions with coefficients found by LS appear to have higher maximal absolute errors. Correlations and adjusted $r^{2}$ are lower than these shown in Table 5. The last line presents the accuracy of learning style prediction calculated as complementary to the model's error indicated by the normalized RMSE as in (Nogueira et al., 2013). For all the learning styles, regression coefficients calculated by the LS method lead to better accuracy.

\subsection{Model validation}

While the first experiment was used to determine regression coefficients for calculation of playing styles and to optimize them for playing in affectively adaptive mode, the second experiment was conducted to validate playing style recognition applying the optimized regression coefficients. Table 9 presents statistics about playing style prediction for the validation experiment. Results for the Logician style appear to be better for regression coefficients found by SI than these optimized by the LS method, which can be due to the relatively small number of participants $(\mathrm{N}=30)$. The last line shows the accuracy of playing style prediction as complementary to the model's error indicated by the normalized RMSE. Paired T-tests performed on the accuracy scores show there is a statistically significant difference in calculation of all playing styles and, therefore, prove that the LS method performs better than SI ( $p<.05$ for Competitor and Dreamer; $p<.0001$ for Logician and Strategist). As a whole, the accuracy of playing style recognition is very similar to that one of learning style prediction presented in Table 8.

Table 5

Statistical measures of the model accuracy of playing style recognition.

\begin{tabular}{|c|c|c|c|c|c|c|c|c|}
\hline \multirow[t]{2}{*}{ Statistics } & \multicolumn{2}{|c|}{ Competitor } & \multicolumn{2}{|l|}{ Dreamer } & \multicolumn{2}{|l|}{ Logician } & \multicolumn{2}{|l|}{ Strategist } \\
\hline & SI & LS & SI & LS & SI & LS & SI & LS \\
\hline MAE & 33.3333 & 28.6342 & 27.8000 & 28.9975 & 21.5000 & 20.4343 & 30.9209 & 24.9769 \\
\hline RMSE & 11.2886 & 10.5522 & 9.2546 & 8.8952 & 8.7664 & 8.5873 & 12.9998 & 12.4741 \\
\hline$r$ & 0.7916 & 0.8269 & 0.7698 & 0.7921 & 0.8286 & 0.8817 & 0.6329 & 0.7130 \\
\hline$r^{2}$ & 0.6266 & 0.6839 & 0.5927 & 0.6276 & 0.6866 & 0.7774 & 0.4006 & 0.5084 \\
\hline adjusted $r^{2}$ & 0.6025 & 0.6635 & 0.5664 & 0.6035 & 0.6663 & 0.7630 & 0.2936 & 0.3241 \\
\hline
\end{tabular}

MAE - maximal absolute error.

RMSE - root mean square error. 
Table 6

Statistical comparison of mean values of playing styles obtained by SI and LS.

\begin{tabular}{lllll}
\hline Statistic & $\begin{array}{l}\text { Competitor SI/ } \\
\text { LS }\end{array}$ & $\begin{array}{l}\text { Dreamer SI/ } \\
\text { LS }\end{array}$ & $\begin{array}{l}\text { Logician SI/ } \\
\text { LS }\end{array}$ & $\begin{array}{l}\text { Strategist SI/ } \\
\text { LS }\end{array}$ \\
\hline $\begin{array}{c}p(\mathrm{~T} \leq \mathrm{t}) \text { two- } \\
\text { tail }\end{array}$ & 0.0886 & 0.0268 & 0.0001 & 0.9951 \\
$\begin{array}{l}\text { paired } S D \\
\text { Cohen } d\end{array}$ & 14.5616 & 10.9836 & 15.6836 & 9.6082 \\
& 0.0804 & 0.0870 & -0.0701 & 0.0003 \\
\hline
\end{tabular}

\section{Discussion}

Results presented in the previous section provide eloquent answers to the research questions stated in the introduction. With regard to the first question (RQ1), multiple linear regression over performance metrics of game tasks related to specific style appears to be an appropriate method for an ecologically valid automatic recognition of playing styles. The first experiment proved that the model with regression coefficients found by a heuristic approach relaying on experience and observation knowledge of domain experts can recognize playing style with similar statistical measures as that one with coefficients optimized by the least squares method using styles measured by ADOPTA PSQ as training dataset (Table 5). Therefore, both the heuristic and optimized regression models present well the dependency between the task metrics and corresponding style.

The second research question (RQ2) looks for the effect of affective gameplay adaptation on performance metrics of game tasks used as explanatory variables for estimation of playing style. Relative statistically significant improvements in task effectiveness, efficiency and difficulty (Table 3) and in some metrics for the Strategist style (Table 4) in affective adaptation mode have from small to medium effect size and reveal the beneficiary effect of affect-based DDA. Replacement of still facial expressions applied as a basis for affective
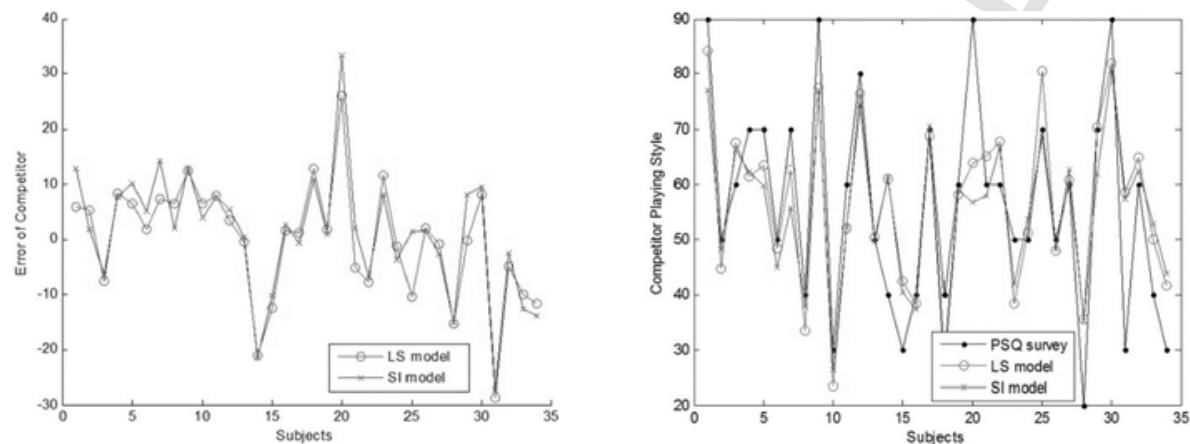

Fig. 4. Errors and playing styles for Competitor obtained by questionnaire, structured interviews and least squares.
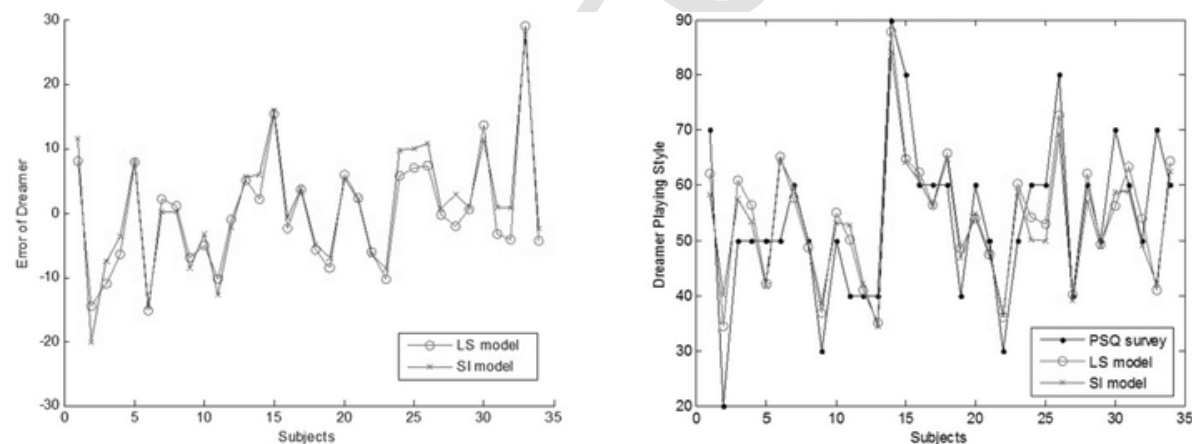

Fig. 5. Errors and playing styles for Dreamer obtained by questionnaire, structured interviews and least squares.
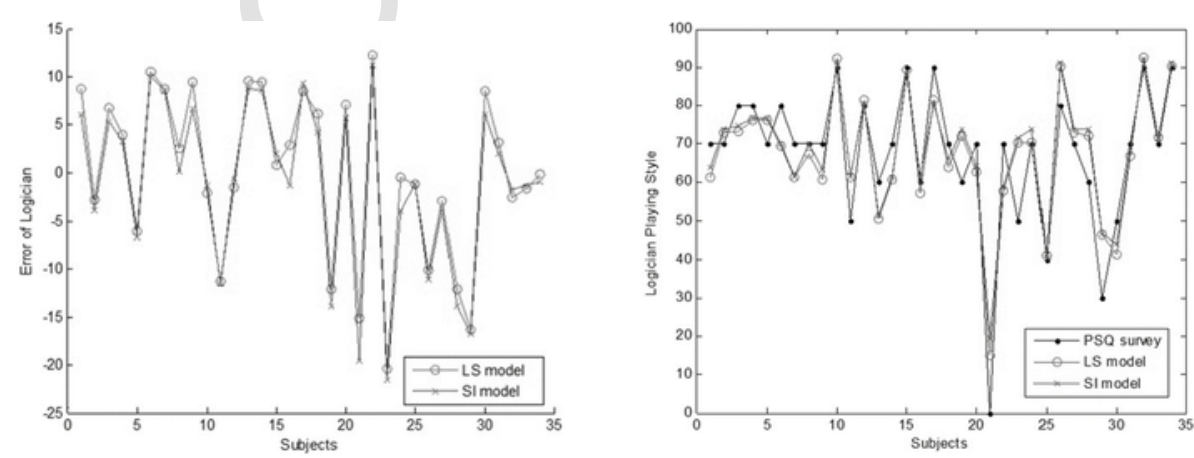

Fig. 6. Errors and playing styles for Logician obtained by questionnaire, structured interviews and least squares. 

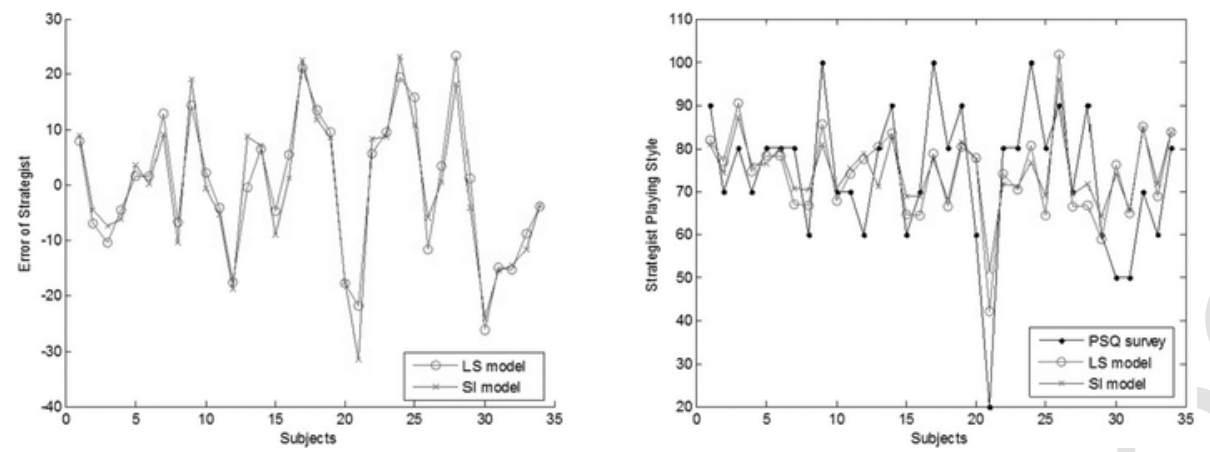

Fig. 7. Errors and playing styles for Strategist obtained by questionnaire, structured interviews and least squares.

Table 7

Correlations of reported playing styles (ADOPTA PSQ) with learning styles (Honey and Mumford's LSQ).

\begin{tabular}{llll}
\hline Learning style & Playing style & $\mathrm{r}$ & $\mathrm{d}$ \\
\hline Activist & Competitor & 0.8379 & 0.0318 \\
Reflector & Discoverer & 0.8144 & 0.2240 \\
Theorist & Logician & 0.7230 & 0.2491 \\
Pragmatist & Strategist & 0.8134 & 0.1096 \\
\hline
\end{tabular}

$p<.0000, \mathrm{~N}=34$.

adaptation (Bontchev, 2016) by video expressions combined with arousal inferred by electrodermal activity (Bontchev \& Vassileva, 2016) result in higher improvement of game outcomes with doubled effect size.

The third research question (RQ3) is about the accuracy of in-game recognition of playing styles. For estimation of the measuring accuracy, we applied the approach of Nogueira et al. (2013) employing the normalized residual sum of squares as a relative indicator of the model's error. The model validation experiment proved that regression coefficients found by SI with domain experts can recognize playing style with an average accuracy of $71.19 \%$. On the other hand, regression coefficients estimated by the LS method (Table 9) show an average accuracy of estimation of playing styles equal to $76.51 \%$. For all the style scores, the estimation accuracy of the LS method always appears to be better than that of the SI method. As expected, the accuracy of Pragmatist style estimation is relatively lower due to the lower values of adjusted $r^{2}$ for both the SI and LS methods.

As expected, the analysis revealed strong correlations of playing styles reported by ADOPTA PSQ with learning styles measured by Honey and Mumford's LSQ (Table 7). This fact encouraged us to investigate statistical measures of the model accuracy of learning style prediction (Table 8). We found the average accuracy of learning style prediction by the SI regression model to be $79.50 \%$ and that of the LS regression model to amount to $82.71 \%$. Therefore, both the models are able to predict accurately not only ADOPTA playing styles but Honey and Mumford's learning styles, as well (research question RQ4).

Table 8

Statistical measures of the model accuracy of learning style prediction.

\begin{tabular}{|c|c|c|c|c|c|c|c|c|}
\hline \multirow[t]{2}{*}{ Statistics } & \multicolumn{2}{|l|}{ Activist } & \multicolumn{2}{|l|}{ Reflector } & \multicolumn{2}{|l|}{ Theorist } & \multicolumn{2}{|c|}{ Pragmatist } \\
\hline & SI & LS & SI & LS & SI & LS & SI & LS \\
\hline MAE & 27.3333 & 29.2530 & 28.4733 & 26.9734 & 38.6667 & 39.4407 & 28.1887 & 26.1420 \\
\hline RMSE & 11.3620 & 11.7942 & 11.3507 & 11.0293 & 13.3789 & 13.5499 & 11.7492 & 11.1194 \\
\hline$r$ & 0.7005 & 0.6853 & 0.6365 & 0.6391 & 0.7683 & 0.7769 & 0.6229 & 0.6566 \\
\hline$r^{2}$ & 0.4907 & 0.4696 & 0.4051 & 0.4085 & 0.5902 & 0.6036 & 0.3881 & 0.4311 \\
\hline adjusted $r^{2}$ & 0.4578 & 0.4354 & 0.3667 & 0.3703 & 0.5638 & 0.5780 & 0.2788 & 0.3295 \\
\hline Accuracy & $78.45 \%$ & $81.25 \%$ & $80.40 \%$ & $82.40 \%$ & $87.79 \%$ & $88.09 \%$ & $71.36 \%$ & $79.09 \%$ \\
\hline
\end{tabular}

$p<.0000, \mathrm{~N}=34$.

MAE - maximal absolute error.

RMSE - root mean square error.

Table 9

Statistical measures of the model accuracy of playing style recognition for the validation experiment.

\begin{tabular}{|c|c|c|c|c|c|c|c|c|}
\hline \multirow[t]{2}{*}{ Statistics } & \multicolumn{2}{|l|}{ Competitor } & \multicolumn{2}{|l|}{ Dreamer } & \multicolumn{2}{|l|}{ Logician } & \multicolumn{2}{|l|}{ Strategist } \\
\hline & SI & LS & SI & LS & SI & LS & SI & LS \\
\hline MAE & 42.9333 & 43.3999 & 35.8177 & 26.1270 & 51.0256 & 55.4588 & 31.8275 & 28.5769 \\
\hline RMSE & 12.4163 & 10.4543 & 14.9991 & 12.1565 & 14.7813 & 15.3213 & 11.6466 & 11.0125 \\
\hline$r$ & 0.8590 & 0.8921 & 0.7711 & 0.7594 & 0.7686 & 0.7412 & 0.6622 & 0.6362 \\
\hline$r^{2}$ & 0.7379 & 0.7958 & 0.5946 & 0.5766 & 0.5907 & 0.5494 & 0.4384 & 0.4048 \\
\hline adjusted $r^{2}$ & 0.7185 & 0.7807 & 0.5646 & 0.5453 & 0.5604 & 0.5160 & 0.3215 & 0.2808 \\
\hline Accuracy & $79.40 \%$ & $84.03 \%$ & $70.51 \%$ & $76.32 \%$ & $70.77 \%$ & $72.16 \%$ & $64.10 \%$ & $73.52 \%$ \\
\hline
\end{tabular}

$p<.0000, \mathrm{~N}=30$.

$\mathrm{MAE}$ - maximal absolute error.

RMSE - root mean square error. 


\section{Limitations}

The present study was planned with several important limitations. First, at all, it aims at an automatic recognition of a specific family of playing styles conceived on top of the Kolb's theory of experiential learning. ADOPTA playing styles are determined over the Processing-Perception continuum and game tasks and performance metrics used for their recognition are selected especially according to the experiential learning theory. For estimation of another family of playing styles, different explanatory variables are to be taken into consideration.

Second, accuracy and other statistics regarding playing style estimation are based on using ADOPTA PSQ. The same goes for accuracy and statistics of learning style estimation and use of Honey and Mumford's LSQ. Any bias in styles estimated through these questionnaires will result in biased statistics of automatic style estimation built in the game.

Next, affective adaptation was implemented in 'Rush for Gold' by applying player's emotions inferred through still facial expressions captured by Web camera once per second. Better approaches for inference of emotional state of the player might result in higher improvement of performance metrics of game tasks used for player style recognition.

Finally, the study was limited by the relatively small number of participants $(\mathrm{N}=34)$ for the first experiment and $\mathrm{N}=30$ for the second one). The limitation was imposed by the extended procedure of the experiment including a demonstration, an assisted training session and two game sessions in random order - one without and another with affective adaptation control. A higher number of participants would require longer time and overhead and, not last, a web-based video game instead of the current desktop version of 'Rush for Gold'. As well, a web-based experimental instrument will allow testing reliability of playing style recognition by performing multiple game sessions with given player in different gameplay modes.

\section{Conclusions}

Adaptation of video games based on playing/learning style of the player/learner remains a challenge for game designers and game-based learning practitioners. Together with adaptation methods applying player's performance or emotional state, it forms a solid fundament for holistic implementation of player-centric game design (Bontchev, 2016). Therefore, validity and accuracy of playing style recognition appear crucial for style-based adjustment of digital games, especially when implemented in an ecologically valid context.

The article presented an approach for automatic recognition of both playing and learning styles based on the Kolb's theory of experiential learning. It revealed how multiple linear regression can be used for modeling dependency between performance metrics of game tasks and corresponding style of playing/learning in a simple yet powerful way. By means of identification and validation experiments, it was proved that regression model coefficients found by both heuristic and optimization approaches can be applied for effective recognition of styles with high accuracy. Future work is going to include experiments with a web-based version of the same game following a simplified experimental procedure in order to involve a higher number of participants. The model can be applied for tailoring didactical content and tasks in the game to recognized playing or learning styles, which is proven for bringing benefits with regard to better learning outcomes (Soflano et al., 2015). Additionally, style-based adaptation of video game features can be used for adjusting learning goals, feedback, error prevention and recovery, and understanding of goals and, thus, to enhance player's satisfaction and motivation (Birk et al., 2015), effectiveness, immersion, learnability and other attributes of educational playability as a measure of player experience in educational games (Ibrahim, Gutiérrez, González Sánchez, \& Padilla Zea, 2012).

The automatic recognition of both playing and learning styles, together with adaptation of various features concerning game mechanics, dynamics, and/or contents, can be generalized for different types and genres of video games, because in any game we can find some appropriate metrics of player outcomes related to a specific style, which can be applied as explanatory variables. Recognized playing and/or learning styles are appropriate for implementation of style-based adaptation not only of didactic content in educational games (Orji et al., 2013; Vassileva, 2012), but for adjusting various features of mechanics of any applied game for single player or multiple players according to the personal style and traits of the individual player, as well. On the other hand, studies of Fairclough and Gilleade (2012), Novak et al. (2012), Yannakakis and Paiva (2014, pp. 459-471) and much more including the present research have proved that affect-based adaptation is able to increase playing outcomes and, as well, to enhance overall game playability. Therefore, style-based adaptation is preferable to be applied not in isolation, but together with methods for affective adaptation of gameplay using inference of player emotional state based on efficient, accurate and non-obtrusive techniques.

\section{Acknowledgements}

The research leading to these results has received funding from the People Programme (Marie Curie Actions) of the European Union's 7th Framework Programme FP7/2007-2013/project ADAPTIMES (ADAPTIve player-centric serious video gaMES) under REA Grant agreement No 624184 and, as well, from the project APOGEE (innovative platform for smArt adaPtive videO GamEs for Education) funded by the Bulgarian NSF under Grant agreement no. DN12/7/ 2017.

\section{References}

Aleksieva-Petrova, A., Petrov, M., Bontchev, B., 2011. Game and learmer ontology model. Ohrid, Macedonia. In: Int. scientific conf. computer science'2011. pp. 392-396.

Bartle, R., 1996. Hearts, clubs, diamonds, Spades: Players who suit MUDs, available at: http://mud.co.uk/richard/heds.htmAccessed 29 July 2016.

Bateman, C., Boon, R., 2005. In: 21 st century game design Vol. 1, Charles River Media, London.

Bateman, C., Lowenhaupt, R., Nacke, L.E., 2011, September. Player typology in theory and practice. In: Proc. of think design play: The 5th int. conf. of DIGRA, available online: http://www.digra.org/dl/db/11307.50587.pdfAccessed 29 July 2016.

Birk, M.V., Toker, D., Mandryk, R.L., Conati, C., 2015, June. Modeling motivation in a social network game using player-centric traits and personality traits. In: Int. Conf. on user modeling, adaptation, and personalization. Springer, pp. 18-30.

Bontchev, B., 2016, April. Holistic player modelling for controlling adaptation in video games. In: Proc. of 14th int. conf. e-society, Vilamoura, Portugal. pp. 11-18.

Bontchev, B., Vassileva, D., 2016. Affect-based adaptation of an applied video game for educational purposes. submitted to Interactive Technology and Smart Education Emerald.

Caillois, R., Barash, M., 1961. Man, play, and games. University of Illinois Press.

Chang, D.M.J., 2013. Dynamic difficulty adjustment in computer games. In: Proc. of 11 th ann. interact. multimedia systems conf.. Univ. of Southampton, UK.

Cowley, B., Charles, D., Black, M., Hickey, R., 2013. Real-time rule-based classification of player types in computer games. User Modeling and User-adapted Interaction 23 (5), 489-526.

Curry, L., 1981. Learning preferences in continuing medical education. Canadian Medical Association Journal 124 (5), 535.

Edwards, R., Holland, J., 2013. What is qualitative interviewing?. Bloomsbury Academic. 
Etheredge, M., Lopes, R., Bidarra, R., 2013. A generic method for classification of player behavior. In: Second workshop on artificial intelligence in the game design process. pp. 1-7.

Fairclough, S., Gilleade, K., 2012, October. Construction of the biocybernetic loop: A case study. In: Proc. of the 14th ACM int. conf. on multimodal interaction. ACM, pp. 571-578.

Fairclough, S.H., Venables, L., 2006. Prediction of subjective states from psychophysiology: A multivariate approach. Biological Psychology 71 (1), 100-110.

Freedman, D.A., 2009. Statistical models: Theory and practice. Cambridge University Press.

van de Geer, S., 2001. Least squares estimation with complexity penalties. Mathematical Methods of Statistics 10 (3), 355-374.

Heeter, C., Winn, B., 2008. Gender identity, play style, and the design of games for classroom learning. In: Beyond Barbie and Mortal Kombat: New perspectives on gender and gaming. pp. 281-300.

Honey, P., Mumford, A., 1992. The manual of learning styles, $3^{\text {rd }}$ ed. Peter Honey, Maidenhead, Berkshire, UK.

Ibrahim, A., Gutiérrez, F.L., González Sánchez, J.L., Padilla Zea, N., 2012, January. Educational playability analyzing player experiences in educational video games. In: Proc. of 5th int. conf. on advances in computer-human interactions ACHI.

Keirsey, D., 1998. Please understand me II: Temperament, character, intelligence. Prometheus Nemesis Book Co.. ISBN: 1-885705-02-6.

Klawe, M., 1999. Computer games, education and interfaces: The E-GEMS project. Graphics Interface 36-39.

Kolb, D., 1984. Experiential learning: Experience as the source of learning and development. Prentice Hall, Englewood Cliffs, New Jersey.

Lazzaro, N., 2008. The four fun keys. In: Isbister, K., Schaffer, N. (Eds.), Game usability advancing the player experience. Morgan Kaufman, pp. 317-343.

Magerko, B., Heeter, C., Fitzgerald, J., Medler, B., 2008. Intelligent adaptation of digital game-based learning. In: Proc. of the 2008 conf. on future Play: Research, play, share. ACM, pp. 200-203.

Malone, T.W., 1981. Toward a theory of intrinsically motivating instruction. Cognitive Science 5, 333-369.

Nacke, L.E., Bateman, C., Mandryk, R.L., 2013. BrainHex: A neurobiological gamer typology survey. Entertainment Computing 5 (1), 55-62.

Nogueira, P.A., Rodrigues, R., Oliveira, E., 2013. Real-time psychophysiological emotional state estimation in digital gameplay scenarios. Engineering Applications of Neural Networks, Springer Berlin Heidelberg 243-252.

Novak, D., Mihelj, M., Munih, M., 2012. A survey of methods for data fusion and system adaptation using autonomic nervous system responses in physiological computing. Interacting with Computers 24, 153-172.
Orji, R., Mandryk, R.L., Vassileva, J., Gerling, K.M., 2013. Tailoring persuasive health games to gamer type. In: Proc. of CHI' 2013. pp. 2467-2476.

Rosenthal, J.A., 1996. Qualitative descriptors of strength of association and effect size. Journal of Social Service Research 21 (4), 37-59.

Soflano, M., Connolly, T.M., Hainey, T., 2015. An application of adaptive games-based learning based on learning style to teach SQL. Computers \& Education $86,192-211$.

Stewart, B., 2011, September. Personality and play styles: A unified model, gamasutra, available at: http://www.gamasutra.com/view/feature/6474/Accessed 29 July 2016.

Toups, Z.O., Graeber, R., Kerne, A., Tassinary, L., Berry, S., Overby, K., et al., 2006. A design for using physiological signals to affect team game play. Foundations of Augmented Cognition 134-139.

Vassileva, D., 2012. Adaptive e-learning content design and delivery based on learning styles and knowledge level. Serdica Journal of Computing 6 (2), 207-252.

Wong, C., Kim, J., Han, E., Jung, K., 2009. Human-centered modeling for style-based adaptive games. Journal of Zhejiang University - Science a 10 (4), 530-534.

Yannakakis, G.N., Paiva, A., 2014. Emotion in games, handbook on affective computing.

Yee, N., 2006. Motivations of play in online games. Cyber Psychology and Behavior 9 (6), 772-775.

Boyan Bontchev has $\mathrm{PhD}$ in Parallel Processing. He worked as software engineer and project manager for many European industrial and research projects. Since 2012, he is Professor at Faculty of Mathematics and Informatics, Sofia University. For the period 2014-2016, he was a Marie Curie research fellow at Brainstorm Multimedia (Spain) responsible for the ADAPTIMES project.

Dr. Olga Georgieva is Associate Professor in Informatics, Faculty of Mathematics and Informatics, Sofia University, Bulgaria. She received $\mathrm{PhD}$ in Process Control at Bulgarian Academy of Sciences. Her strong background and research interests include analysis and development of intelligent systems, data mining and software system analysis. 